\title{
Pulmonary arterial hypertension: an update
}

\author{
E. S. Hoendermis
}

Published online: 15 November 2011

(C) The Author(s) 2011. This article is published with open access at Springerlink.com

\begin{abstract}
Pulmonary arterial hypertension (PAH), defined as group 1 of the World Heart Organisation (WHO) classification of pulmonary hypertension, is an uncommon disorder of the pulmonary vascular system. It is characterised by an increased pulmonary artery pressure, increased pulmonary vascular resistance and specific histological changes. It is a progressive disease finally resulting in right heart failure and premature death. Typical symptoms are dyspnoea at exercise, chest pain and syncope; furthermore clinical signs of right heart failure develop with disease progression. Echocardiography is the key investigation when pulmonary hypertension is suspected, but a reliable diagnosis of $\mathrm{PAH}$ and associated conditions requires an intense work-up including invasive measurement by right heart catheterisation. Treatment includes general measures and drugs targeting the pulmonary artery tone and vascular remodelling. This advanced medical therapy has significantly improved morbidity and mortality in patients with PAH in the last decade. Combinations of these drugs are indicated when treatment goals of disease stabilisation are not met. In patients refractory to medical therapy lung transplantation should be considered an option.
\end{abstract}

Keywords Pulmonary arterial hypertension - Diagnostics . Therapy $\cdot$ Review

E. S. Hoendermis $(\bowtie)$

Department of Cardiology, University Medical Centre Groningen,

University of Groningen,

PO Box 30.001, 9700 RB Groningen, the Netherlands

e-mail: e.s.hoendermis@thorax.umcg.nl

\section{Introduction}

In recent years a new definition, classification and treatment options of pulmonary hypertension (PH) were developed and are described in the European Society of Cardiology (ESC) guidelines of 2009 [1]. More than 30 diagnoses can now be classified in one of the five groups of PH. The definition of $\mathrm{PH}$ is set by an invasively assessed mean pulmonary artery pressure (PAP) of $\geq 25 \mathrm{mmHg}$. Pulmonary arterial hypertension (PAH) is the group 1 of the $\mathrm{PH}$ classification (Table 1) and represents the type of $\mathrm{PH}$ in which spectacular advances in the understanding and treatment have been achieved in the past decade. In the new guidelines PH on exercise was withdrawn because the mean PAP at exercise can exceed $30 \mathrm{mmHg}$ in healthy subjects and is dependent on age and type and level of exercise.

\section{Classification, aetiology and prognosis}

In PAH pulmonary pressure elevation has its origin in the precapillary pulmonary vascular system. The histological changes consist of intima and media hypertrophy, vessel obliteration, in-situ thrombosis and development of plexiform lesions. These histological changes are similar in all (clinically so different) conditions combined in the PAH group, at least at a certain stage. On the other hand plexiform lesions are not present in any other group of $\mathrm{PH}$ [2]. PAH can be subdivided into different groups.

Idiopathic PAH is a very rare condition with an incidence of 2-6/million adult population/year [3, 4]. Most of the patients are women in the third to fourth 
Table 1 Updated classification of pulmonary arterial hypertension

1. Pulmonary arterial hypertension
1.1 Idiopathic
1.2 Heritable
1.3 Drugs and toxins induced
1.4 Associated with
1.4.1 Connective tissue diseases
1.4.2 HIV infection
1.4.3 Portal hypertension
1.4.4 Congenital heart disease
1.4.5 Schistosomiasis
1.4.6 Chronic hemolytic anaemia
1.5 Persistent pulmonary hypertension of the newborn
1' Pulmonary veno-occlusive disease / pulmonary capillary
haemangiomatosis

decade of life. Idiopathic PAH is a rapidly progressive disease with an untreated survival of only 2.8 years $[3,4]$.

When germ-line mutations are present in idiopathic $\mathrm{PAH}$, this is referred to as heritable PAH. Heritable PAH also includes clinical familial cases with or without identified germ-line mutations. Mutations are identified on the transforming-growth-factor- $\beta$ (TGF- $\beta$ ) receptor family, such as the BMPR II gen, Alk 1 gen and endoglin gene [5]. Mutations in the BMPR II gene have been found in $20 \%$ of IPAH patients and in $70 \%$ of familial cases. However, the penetrance is very variable. Echocardigraphic screening of first-degree family members is advised. Patients with heritable PAH have an even worse outcome than IPAH patients [6].

PAH can be associated with exposure to drugs and toxins, especially anorectic drugs as aminorex and fenfluramine. Moreover, there is also a suspected association with the use of cocaine, (meth-) amphetamines, L-tryptophan, mitomycin $\mathrm{C}$ and selective serotonin reuptake inhibitors [1].

Very common is an association of PAH with connective tissue disease. The highest incidence of the development of $\mathrm{PAH}$ is known in scleroderma patients, especially with the CREST syndrome as scleroderma subentity (10-20\% develop PAH), followed by systemic lupus erythematosus (SLE, 10\%) [7, 8]. Patients with PAH in connective tissue disease have a deleterious clinical course and a worse prognosis. In those with scleroderma echocardiographic screening is advised once a year.

Also HIV infection is one of the established risk factors for PAH, representing approximately $7 \%$ of all new cases of PAH in a French PAH registry [4]. The exact pathogenesis is unknown. The viral antigens that are found in the endothelial wall might induce pathological growth and proliferation next to the chronic inflammatory state and immune activation in HIV infection. The presence of PAH in HIV patients is an independent risk factor for survival, which is 3.6 years from the moment of diagnosis of PAH $[9,10]$.

Porto pulmonary hypertension is an association of portal hypertension and PAH. It has an incidence of $2-9 \%$ in all patients with structural liver disease and up to $16 \%$ in patients with advanced liver disease. However, no clear relation between portal vein pressure, hepatic function and development of PAH can be shown. The prognosis is poor with a 5-year survival rate of $14 \%$ [11]. A mPAP $>35 \mathrm{mmHg}$ in combination with an elevated pulmonary vascular resistance (PVR) is regarded as an important risk factor for liver transplantation.

PAH is common in congenital heart disease (CHD) [12] and forms a special subgroup with essential differences from other PAH conditions, mainly concerning clinical course, prognosis and heterogeneity of the group. This was taken into account in the last modification of the guidelines by updating the clinical and anatomical-pathophysiological classification of PAH-CHD. Increased blood flow in the pulmonary vasculature caused by a systemic to pulmonary shunt is a prerequisite for the development of CHD-PAH . Additional pressure overload, as in post-tricuspid shunts (VSD, aorto-pulmonary window, persistent ductus botalli) accelerates this development. In the first stage the vascular changes are reversible and therefore curable by closure of the shunt. At a certain point of no return irreversible damage of the pulmonary vascular system develops and the prognosis depends on multiple factors such as associated heart defect, location and dimension of the shunt and correction status (closed or unclosed shunt). Patients with closed shunts who develop PAH probably have a prognosis similar to that in IPAH whereas patients with a large, unrestricted open shunt finally develop reversal of the shunt, the so-called Eisenmenger physiology, a condition with a relatively good survival in adults but a lot of morbidity and risks [13].

PAH associated with schistosomiasis (incidence approximately $4-5 \%$ ) was included in the PAH group in the last guidelines because clinical and histological characteristics are similar to other PAH conditions in recent studies. Mechanisms are probably portal hypertension in hepatosplenic schistosomiasis and local inflammation in the pulmonary vessels by schistosomiasis eggs. Given the number of patients with schistosomiasis worldwide, PAH complicating the disease can become an important issue [14].

Chronic haemolytic anaemia such as sickle cell disease, thalassaemia, hereditary spherocytosis, stomatocytosis, and microangiopathic haemolytic anaemia may result in PAH.

Persistent $\mathrm{PH}$ of the newborn is a clinical syndrome in which the pulmonary vascular system fails to adapt to 
extra-uterine circulation. It should not be mixed with paediatric PAH which comprises a heterogenous spectrum of diseases, IPAH and CHD-PAH being the most common [15].

Subgroup 1' comprises pulmonary veno-occlusive disease (PVOD) and pulmonary capillary haemangiomatosis because histopathologically there is overlap between the two features. They share characteristics with the PAH group, but also show important differences as a high incidence of negative response to advanced PAH medication [16]. So this condition has become a distinct category. The diagnosis is challenging as there is no non-invasive test to give a definite diagnosis. The gold standard examination is open lung biopsy, an extremely high-risk procedure in PAH patients.

\section{Diagnosis}

A diagnostic algorithm for the diagnosis of $\mathrm{PH}$ and for classification in $\mathrm{PAH}$ and the other different $\mathrm{PH}$ groups and subgroups is available in the current guidelines (Fig. 1). In general, once PH is suspected, common causes have to be diagnosed or ruled out first. The most common causes by far are left heart disease and lung disease. If one of these diagnoses is confirmed and the pulmonary pressure is not exceeding moderate elevation (not 'out of proportion'), invasive evaluation is not necessary as, according to current data, the diagnosis of $\mathrm{PH}$ in these conditions has no additional therapeutic consequences. As a second step the presence of chronic thromboembolic PH (CTEPH) has to be evaluated before the diagnosis of PAH becomes more likely and invasive work-up is justified.

\section{Symptoms}

Patients with PAH can complain of dyspnoea, exercise intolerance, chest pain, dizziness and syncope, all symptoms that are also common in other cardiopulmonary disorders. For that reason, the diagnosis of PAH is often delayed. In the advanced stage signs of right heart failure are present in most of the patients. A decreased peripheral oxygen saturation due to a decreased cardiac output and in some cases a right-to-left shunt through a patent foramen ovale and physiological intrapulmonary shunts can develop. Furthermore, there can be clinical signs of the associated disease.

Value of diagnostic tests

The ECG can show signs of right ventricular hypertrophy $(\mathrm{RVH})$ and right atrial (RA) dilation. On chest X-ray central pulmonary arterial dilatation and a rarification of the peripheral blood vessels can be seen (Fig. 2). However, neither tests have adequate sensitivity and specificity to be a screening tool.

Echocardiography is the principal screening tool for $\mathrm{PH}$. However, it has important limitations in accuracy of estimating pulmonary pressure. Although there are data showing a good correlation between echocardiographic findings and invasive measurements, there are also several studies reporting significant differences [17-19]. Another limitation is the fact that a measurement of the tricuspid regurgitation (TR)velocity to estimate PAP is not possible in a significant proportion of patients due to lack of TR or a poor acoustic window. In addition to PAP estimation indirect signs of elevated PAP such as pulmonary regurgitation velocity, acceleration time of the antegrade Doppler signal across the pulmonary valve and signs of right ventricular (RV) pressure overload or failure should always be documented to increase accuracy of the method (Fig. 3a-d). In patients with symptoms and increased risk for developing PAH, additional invasive evaluation is necessary, also in case of normal echocardiographic findings. Nevertheless echocardiography remains the non-invasive key investigation and also plays an important role in classification of $\mathrm{PH}$ by excluding or identifying systolic or diastolic left heart dysfunction and valve disease or congenital heart disease as associated condition and gives important prognostic information $[20,21]$. The presence of pericardial effusion and a tricuspid annual excursion (TAPSE) $<15$ are predictors of worse outcome in PAH.

In pulmonary function tests PAH patients normally show no or no more than mild restriction or obstruction at peripheral airway level. But the diffusion capacity of the lung for carbon monoxide (DLCO) is often severely reduced. Although a low DLCO can also be the result of interstitial lung disease or emphysema, the combination of a very low DLCO with a lack of restriction or obstruction is very suspicious for PAH conditions, especially PVOD and collagen vascular disease.

In cardiopulmonary exercise tests $\mathrm{PAH}$ patients can show reduction in $\mathrm{VO} 2 \mathrm{max}$ and increase in ventilatory inefficiency (VE/VCO2); furthermore early lactate acidosis, decreased end-expiratory $\mathrm{CO} 2$ and reduced $\mathrm{O} 2$ pulse are common, but none of those changes are specific for PAH. However, exercise tests have an important role in the follow-up in PAH patients as VO2 max and also a simple 6-minute walk test (6 MWD) are important prognostic markers [22]. A peak $\mathrm{VO} 2<12 \mathrm{ml} / \mathrm{min} / \mathrm{kg}$ or a 6 MWD $<300 \mathrm{~m}$ are predictors of clinical decline and mortality. Shah et al. could show an independent relation between exercise capacity and PVR, RA pressure and CO, the last two reflecting RV function, the strongest predictor of poor outcome in PAH [23]. 
Fig. 1 Diagnostic algorithm for PH (ESC guidelines PH(1)

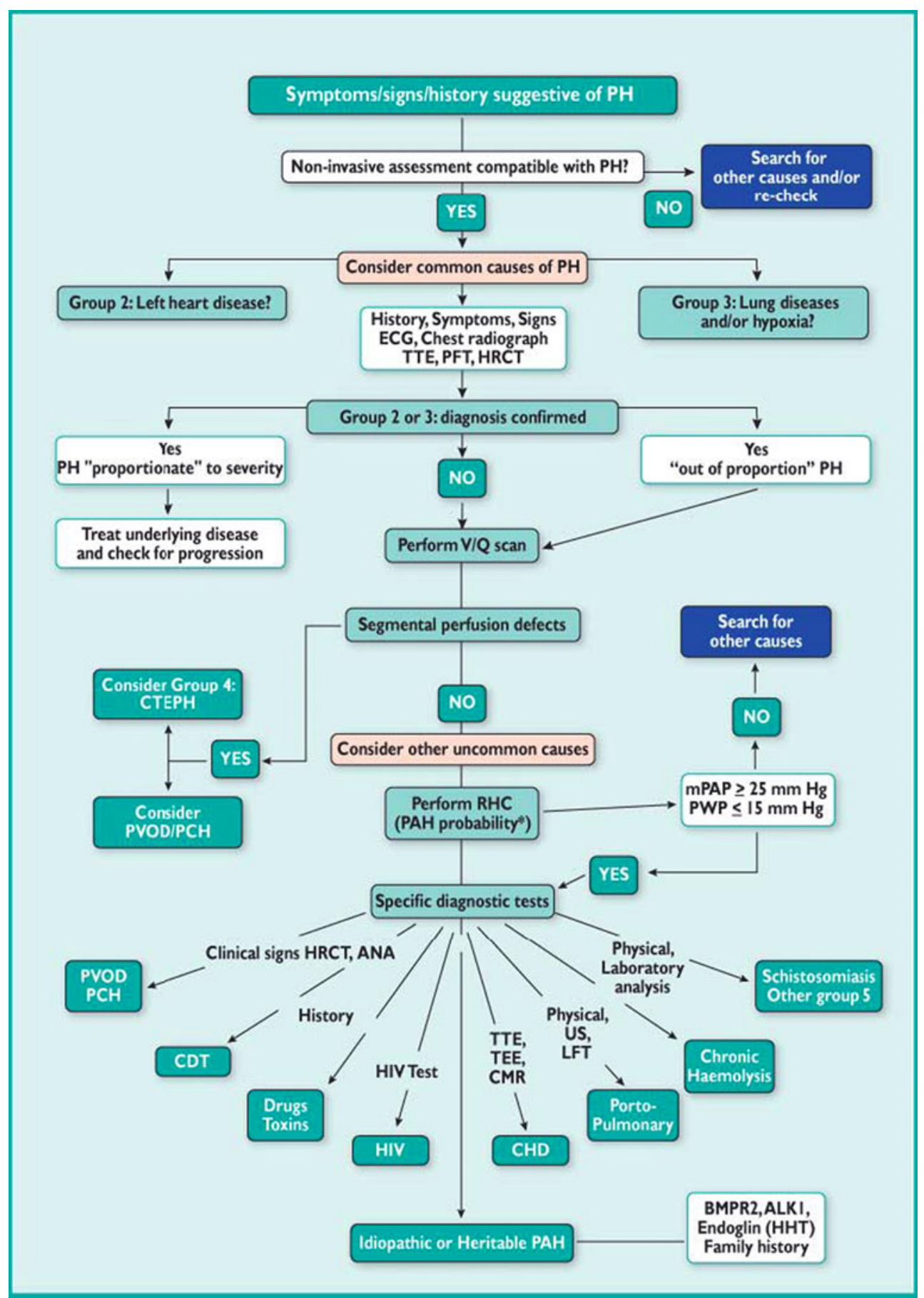

In patients with $\mathrm{PH}$, (HR)CT can show a dilated proximal pulmonary artery, abnormal pulmonary vessels, RV dilation and abnormal septal position. It can rule out emphysema or interstitial lung disease and can give important information for the diagnosis of PVOD [24]. CT angiography is necessary if a ventilation/perfusion scan can not sufficiently rule out thromboembolic lung disease.

MRI can not serve as a screening tool for PAH due to the insufficient accuracy of estimating pulmonary pressure and the availability of MRI. However, MRI is an important upcoming diagnostic tool in $\mathrm{PAH}$ as it is currently considered to be the non-invasive gold standard for evaluation of the right ventricle [25]. It allows a distinct visualisation of the right ventricle, evaluation of RV mass, septal bowing as a consequence of RV pressure or volume overload, and systolic and diastolic volumes of the right and left ventricle, which gives important information not only about compromised RV function but also about interventricular dependency (Fig. 4). As decline of RV function is a key predictor of mortality, MRI provides 


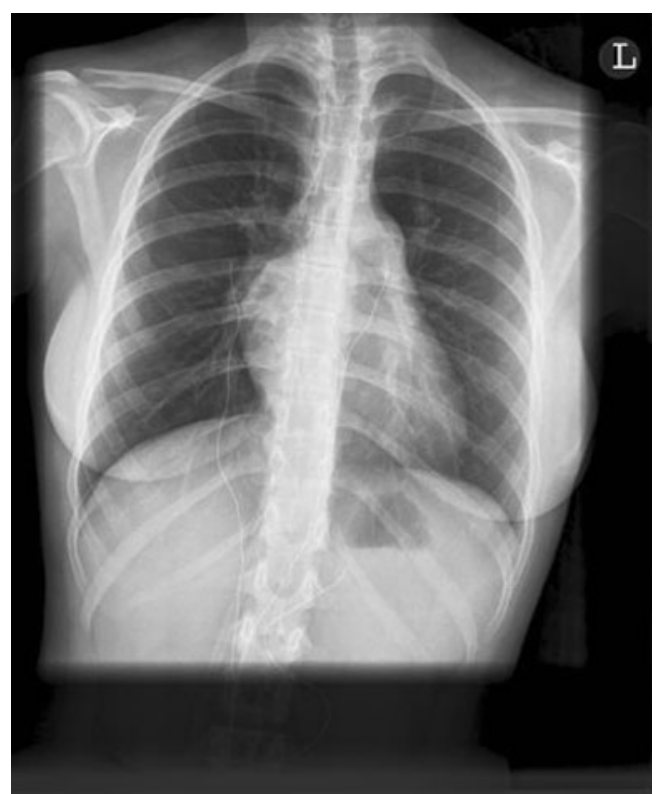

Fig. 2 Chest X-ray of a PAH patient showing a prominent pulmonary artery and enlargement of the right atrium and right ventricle. There is also mild rarification of peripheral lung vasculature
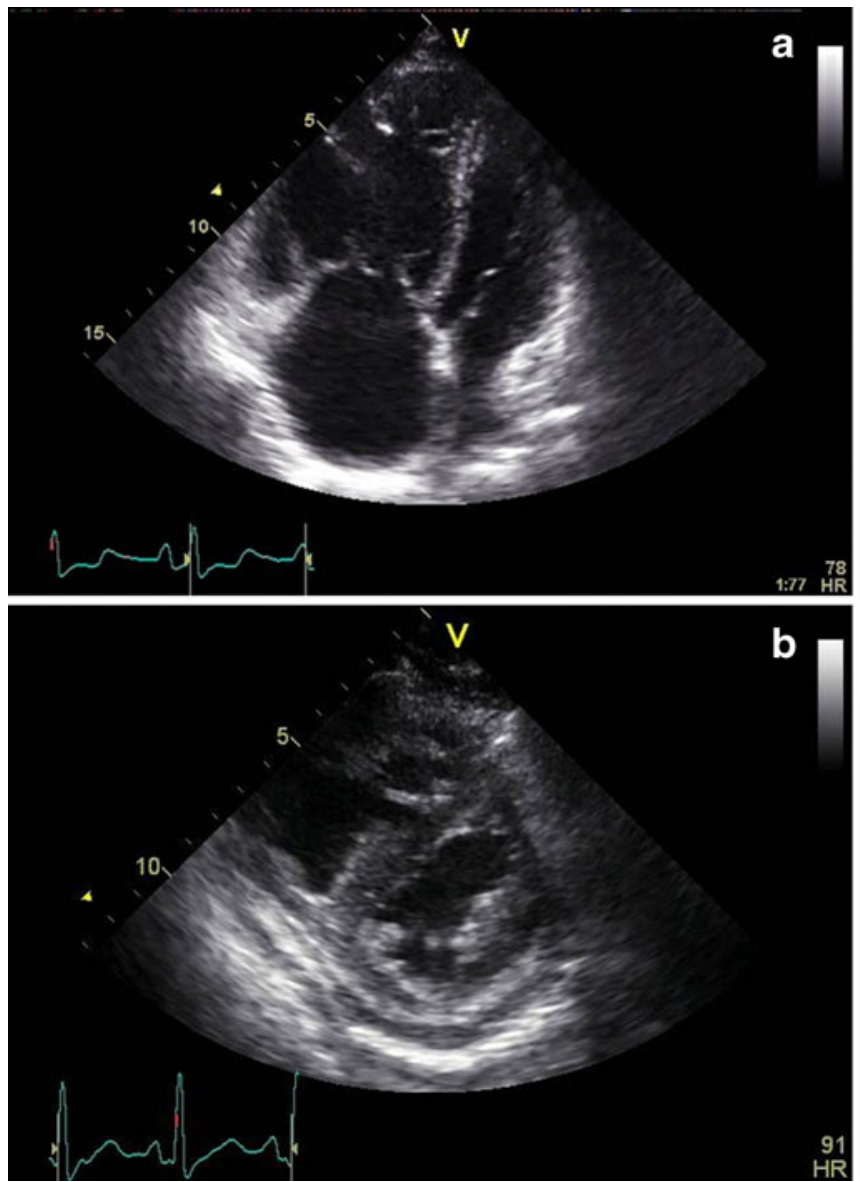

Fig. 3 a-d echocardiography in a patient with portopulmonary PAH. $\mathbf{a}$ and $\mathbf{b}$ apical four-chamber view and parasternal short-axis view showing an enlarged and hypertrophic right ventricle and a flattened interventricular septum, compromising the left ventricle. Pericardial essential information about the stage of the disease and supports therapeutic decisions.

Right heart catheterisation (RHC) is always required to confirm the diagnosis of PAH and to assess haemodynamics. In the same procedure vasoreactivity tests should be performed, which are indicated in PAH to identify patients who might benefit from long-term therapy with calcium channel blockers. The procedure has a low risk in experienced centres (mortality 0.055\%) [26]. The agent of choice in acute vasoreactivity testing is inhaled nitric oxide (NO), because it has the lowest risk profile. Epoprostenol or adenosine intravenously can be used as an alternative. Response to a vasoreactivity test is defined as decrease of the mean PAP by $\geq 10 \mathrm{mmHg}$ reaching a value $\leq 40 \mathrm{mmHg}$ without decreasing cardiac output [27]. RHC should be repeated in patients with clinical deterioration for the evaluation of treatment escalation or timing of (heart)lung transplantation. Right atrial pressure and cardiac output are established prognostic markers.

BNP/NT-proBNP levels reflect the severity of RV dysfunction and are predictors of outcome. A NT-proBNP
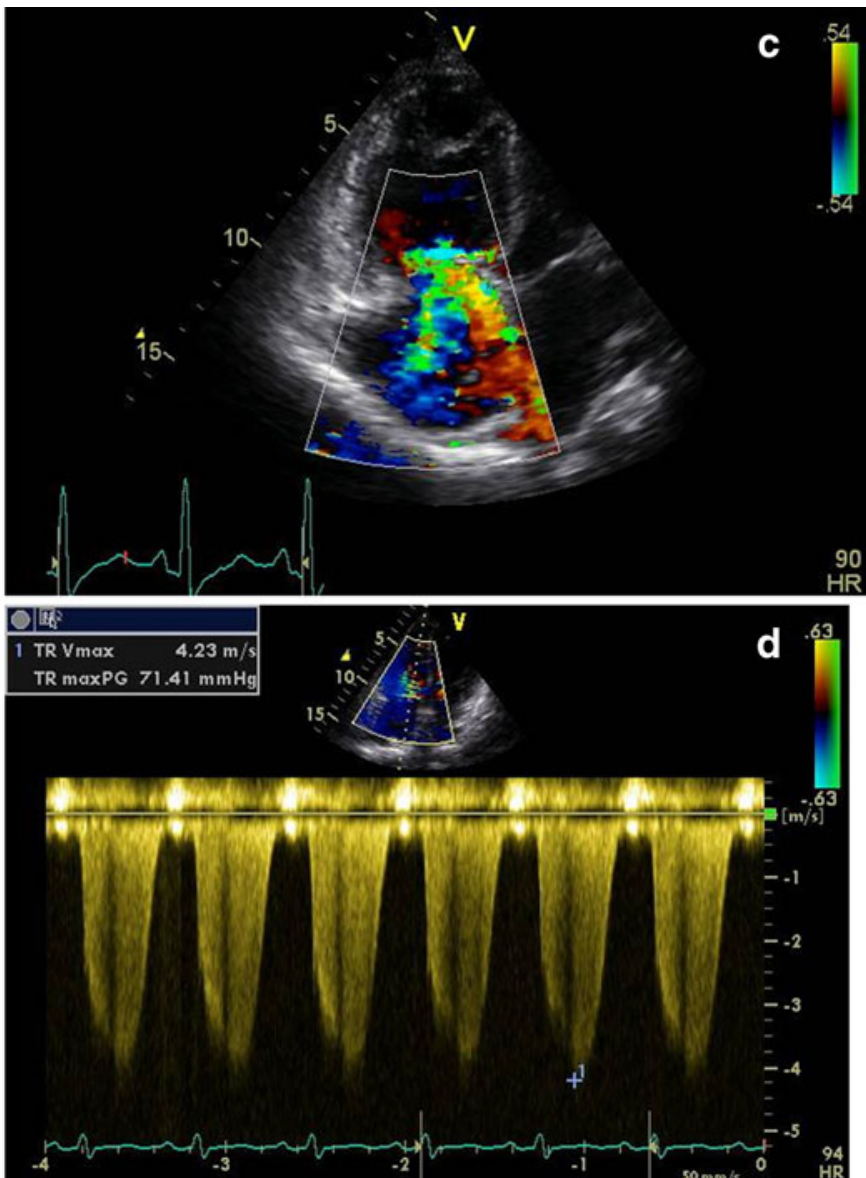

effusion is present, a predictor of worse outcome. $\mathbf{c}$ and $\mathbf{d}$ Significant tricuspid regurgitation with a flow velocity of $4.23 \mathrm{~m} / \mathrm{sec}$ in accordance with a pulmonary artery pressure of $71.4 \mathrm{mmHg}+$ right atrial pressure) 


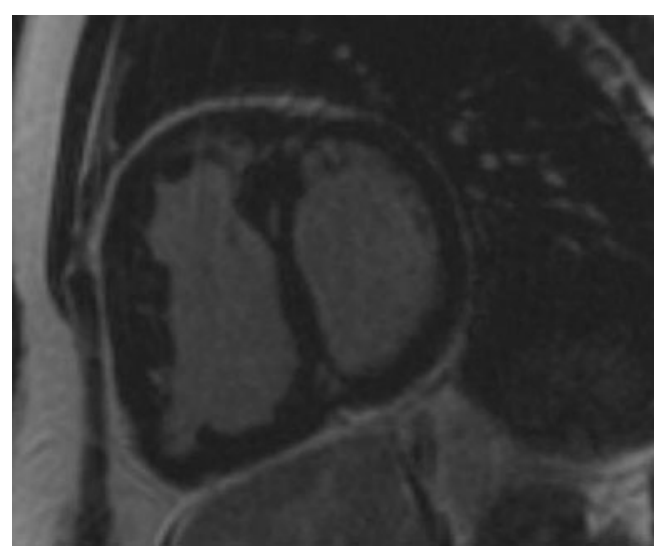

Fig. 4 Cardiac MRI of a PAH patient showing a wide and hypertrophied right ventricle and flattening of the intraventricular septum. With late enhancement myocardial fibrosis can be documented in areas where the right ventricle inserts the septum

cut-off point at $1400 \mathrm{pg} / \mathrm{mL}$ was predictive of a 3-year outcome in 55 patients with severe precapillary PH [28]. But larger studies are needed to confirm or optimise the cutoff value for different subgroups of PAH.

\section{Treatment}

\section{General measurements}

All patients with PAH should be treated in multidisciplinary teams in expert centres [1]. Treatment of the associated disease should be optimised in cooperation with the treating specialists. There are several restrictions and potential lifethreatening conditions to avoid. It cannot be stressed enough that general precautionary measurements in daily life have an important impact on survival in PAH. Pregnancy is contraindicated in all PAH patients. Patients should avoid staying at high altitude level (>1500 m). PAH is a high-risk factor for surgery. Surgery, if unavoidable, should therefore take place in cooperation with a $\mathrm{PH}$ centre. Fluid restriction and diuretics are indicated when right heart failure develops. Beta-blockers are not indicated. Calcium channel blockers (CCB) are only allowed in patients who have responded to invasive vasoreactivity testing. Anticoagulation is indicated (INR 2.0-3.0) to prevent in-situ thrombosis in IPAH, heritable PAH, and PAH due to anorexigens. However, it should be weighted against the risk of bleeding in other PAH subgroups and individually [1,29]. Oxygen therapy is advised in case of $\mathrm{pO} 2<8 \mathrm{kPa}(60 \mathrm{mmHg})$ [1].

\section{Advanced PAH medication}

In the last decade advanced medication targeting the pulmonary vascular tone has become available and could essentially contribute to a better outcome in patients with
PAH. Currently there are three groups with different pathophysiological pathways available: prostanoids, endothelin receptor antagonists (ERA) and phosphodiasterase-5 inhibitors (PDE-5 inhibitors). All three groups reached the status of established PAH therapy. However, most of the studies were conducted in patients with IPAH, heritable $\mathrm{PAH}$, drug-induced $\mathrm{PAH}$ and $\mathrm{PAH}$ associated with connective tissue disease. The data are limited in CHD-PAH. There is one randomised study available for the subgroup with Eisenmenger physiology[30] and PAH-CHD patients are sometimes small subgroups in larger randomized studies with PAH. Data are even more limited in PAH associated with HIV [31], portopulmonary PAH [32], haemolytic anaemia and schistosomiasis. Randomised studies are lacking in these subgroups. There is currently not enough evidence that advanced PAH drugs improve outcome in other forms of $\mathrm{PH}$ than PAH (group 2 to 5 of $\mathrm{PH}$ classification).

\section{Prostanoids}

As a substitute for the lack of endogenous prostacyclin, which is produced by endothelial cells, prostacyclin (epoprostenol) was introduced 1984 as a continuous infusion for the treatment of PAH. In 1996, before the era of oral PAH drugs began, a randomised study could document that the use of epoprostenol improved clinical status, haemodynamics and survival compared with conventional therapy [33]. For use in patients with functional class IV it is still the only drug with a level of evidence A and therefore the drug of choice. An important disadvantage is the need for continuous administration of the drug through a central venous line with a portable infusion pump. Catheter-related complications (infection, thrombosis) as well as emergency situations with rebound $\mathrm{PH}$ caused by accidental discontinuation of the drug are often reported. In the meantime prostacyclin analogues have been developed which can be administered intravenously, subcutaneously, orally or by inhalation. Two of them are currently available in the Netherlands: trepostinil and iloprost. Trepostinil has a longer half-life and can be administered subcutaneously. In a placebo-controlled study improvement of symptoms and haemodynamics could be shown [34]. However, the subcutaneous administration is associated with pain at the injection site in $85 \%$ of the cases and requires frequent change of injection sites, local anaesthetics or even discontinuation of the drug. Iloprost can be administered through inhalation and acts selectively on pulmonary artery vessels in ventilated regions of the lung. A randomised trial showed significant clinical improvement compared with placebo [35]. However, iloprost has to be inhaled 6-9 times per day (30 min per session) to reach an effect comparable with other prostanoids. 
Table 2 Medication for advanced PAH currently available in the Netherlands

\begin{tabular}{|c|c|c|}
\hline Substance class & Drug & Special consideration \\
\hline ERA & $\begin{array}{l}\text { Bosentan (Tracleer) } \\
\text { Ambrisentan (Volibris) }\end{array}$ & $\begin{array}{l}\text { Can cause elevated liver function tests, (Bosentan }>\text { Ambrisentan) } \\
\text { Monthly lab monitoring indicated }\end{array}$ \\
\hline PDE-5-inhibitor & $\begin{array}{l}\text { Sildenafil (Revatio) } \\
\text { Tadalafil (Adcirca, Cialis) }\end{array}$ & $\begin{array}{l}\text { No combination with No-donors, nitrates. } \\
\text { Can induce visual disturbances }\end{array}$ \\
\hline Prostanoids & $\begin{array}{l}\text { Iloprost inhaled (Ventavis) } \\
\text { Trepostinil (Remodulin) }\end{array}$ & $\begin{array}{l}6-9 \text { inhalations/day } \\
\text { Continuous subcutaneous infusion } \\
\text { Pain at injection site is very common }\end{array}$ \\
\hline & Epoprostenol i.v. (Flolan) & $\begin{array}{l}\text { Central venous line necessary with risk of infection and thromboembolism } \\
\text { Relatively contraindicated in patients with right-to-left shunts } \\
\text { Prostanoids general: flush, hypotension, headache }\end{array}$ \\
\hline Ca-channel blockers & $\begin{array}{l}\text { Diltiazem } \\
\text { Amlodipine }\end{array}$ & Only indicated in patients who respond to acute vasoractivity tests \\
\hline
\end{tabular}

Endothelin-receptor antagonists

PAH is characterised by elevated plasma and tissue levels of endothelin-1, a strong vasoconstrictor and inductor of smooth muscle cell proliferation. It acts by binding to endothelin receptors (ETA and ETB). Bosentan is a dual receptor antagonist, blocking both receptors. Several randomised clinical studies show that bosentan has beneficial effects on exercise capacity, haemodynamics and the time to clinical worsening [36-39]. The drug is usually well tolerated. One important side effect is an increase of liver enzyme levels in approximately $10 \%$ of the cases. So treatment with bosentan requires monthly monitoring of liver function. Sometimes dose reduction and in rare cases discontinuation of the drug is necessary.

Ambrisentan, a selective ETA receptor antagonist, is also associated with a significant clinical improvement in randomised trials [40], although data about ambrisentan are more limited. Of note, in studies with ambrisentan only very few patients presented with an increase of liver enzymes. Still, monitoring of liver function tests is mandatory in all patients treated with ERA. Another selective ETA receptor antagonist, sitaxentan, was withdrawn from the market in December 2010 because of complications caused by increase of liver enzymes. Other side effects of ERA can be peripheral oedema, and pharmacological interaction for instance with coumarins. Furthermore, pregnancy is contraindicated because of the potential teratogenicy of ERA.

\section{PDE-5 inhibitors}

The inhibition of phosphodiesterase- 5 causes an increase of cyclic-GMP, which induces vasodilation and inhibits pulmonary artery remodelling. It also has a positive inotropic effect on the hypertrophic right ventricle. The first PDE-5 inhibitor approved for treatment of PAH was sildenafil. A placebo-controlled trial [41] shows a significant but not dose-dependent increase in the 6 MWD for sildenafil (in an oral dose of 20,40 and $80 \mathrm{mg} 3$ times per
Table 3 Parameters with established importance for assessing disease severity, stability and prognosis in PAH; ESC guidelines $\mathrm{PH}[1]$

6 MWD 6 minute walk distance, $P E$ pericardial effusion, TAPSE tricuspid annual systolic excursion, $R A P$ right atrial pressure, $C I$ cardiac index

\begin{tabular}{lll}
\hline Better prognosis & Determinants of prognosis & Worse prognosis \\
\hline No & Clinical evidence of RV failure & Yes \\
Slow & Rate of progression of symptoms & Rapid \\
No & Syncope & Yes \\
I,II & WHO-FC & IV \\
$>500 \mathrm{~m}$ & 6 MWD & $<300 \mathrm{~m}$ \\
Peak VO2 $>15 \mathrm{ml} / \mathrm{min} / \mathrm{kg}$ & Cardiopulmonary exercise test & Peak VO2 $<12 \mathrm{ml} / \mathrm{min} / \mathrm{kg}$ \\
Normal or near-normal & BNP/NT-proBNP & Very elevated and rising \\
No PE, TAPSE $>20 \mathrm{~mm}$ & Echocardiographic findings & PE, TAPSE $<15 \mathrm{~mm}$ \\
RAP $<8 \mathrm{mmHg}$, & Haemodynamics & RAP $>15 \mathrm{mmHg}$ \\
$\mathrm{CI} \geq 2.51 / \mathrm{min} / \mathrm{m} 2$ & & $\mathrm{CI} \leq 2.01 / \mathrm{min} / \mathrm{m} 2$ \\
\hline
\end{tabular}


day respectively) in 278 patients with mostly IPAH. A randomised controlled trial with tadalafil shows improvement in $6 \mathrm{MWD}$ and a slight increase in time to clinical worsening compared with a placebo group [42]. Tadalafil was approved in 2009 and can be administered in a single oral daily dose. PDE-5 inhibitors must not be combined with other NO donors such as nitrates, because this combination can induce extreme hypotension. Furthermore, the use of protease inhibitors such as ritonavir and indinavir can increase the bioactivity of PDE-5 inhibitors, which has to be taken into account when treating patients with PAH associated with HIV infection. Other possible side effects are visual disorders (such as photosensitivity and colour changes), flushes, and headache and muscle pain.

\section{Follow-up}

Diagnosis of PAH and initiation of therapy with advanced PAH medication has to be the beginning of an intensive and well-structured care. Depending on the WHO functional class initial therapy normally starts with one medical substance according to the guidelines [1]. The medication for advanced PAH that is available in the Netherlands is listed in Table 2. Short-term follow-up is indicated (every 3-4 months). Depending on clinical condition and diagnostic tests, which consist of laboratory tests, exercise tests, echocardiography and, if necessary right heart catheterisation, medical therapy has to be increased when treatment goals are not reached [43, 44] (see criteria of stable or unstable disease: Table 3). In addition C-reactive protein and heart rate, two simply obtainable parameters, have recently been shown to contain prognostic information in PAH $[45,46]$ and can be used alongside. Several forms of combination therapy are established [38, 47, 48] or are currently under investigation. Combination therapy as initial therapy has been discussed, but is not yet an established therapy. If a PAH patient is not responding or even deteriorating under $\mathrm{PAH}$ medication the diagnosis of PVOD should be considered, especially, when the patient tends to develop lung oedema under therapy.

In patients who are unstable despite optimised combination therapy atrioseptostomy can be considered. After passing the atrium septum, by using the Brockenbrough procedure, a small right-to-left shunt is created by balloon inflation to unload the right ventricle at the cost of lower arterial saturation. The size of the shunt is guided by arterial saturation. A pre-interventional RA pressure $>20 \mathrm{mmHg}$ and arterial saturation $<90 \%$ are contraindications for the procedure, which should only be performed in experienced centres considering the high risk [49].

Despite the good results of disease stabilisation with medical combination therapy, PAH remains a disease with a poor prognosis. Listing for lung or heart/lung transplantation in time and close cooperation with a transplantation centre is essential. A recent study shows that mortality of PAH patients on the waiting list for lung transplantation is disproportionate, whereas the outcome after transplantation is similar to other conditions (COPD, idiopathic pulmonary fibrosis) [50].

\section{Conclusion}

Despite the success of disease stabilisation with medical therapy, targeting the pulmonary vascular tone, PAH is still a condition with a poor prognosis. Early diagnosis, goal-oriented treatment in $\mathrm{PH}$ expert centres, development of new drugs and timely listing for lung transplantation will hopefully further improve outcome in this heterogeneous group of patients.

Acknowledgement I want to thank I.C.C. van der Horst, MD, $\mathrm{PhD}$ for his kind revision of the manuscript.

Open Access This article is distributed under the terms of the Creative Commons Attribution Noncommercial License which permits any noncommercial use, distribution, and reproduction in any medium, provided the original author(s) and source are credited.

\section{References}

1. Galiè N, Hoeper MM, Humbert M, et al. Guidelines for the diagnosis and treatment of pulmonary hypertension. Eur heart $\mathrm{J}$. 2009;30:2493-537.

2. Humbert M, Morrell NW, Archer SL, et al. Cellular and molecular pathobiology of pulmonary arterial hypertension. J Am Coll Cardiol. 2004;43:S13-24.

3. Peacock AJ, Murphy NF, McMurray JJV, et al. An epidemiological study of pulmonary arterial hypertension. Eur Respir J. 2007;30:104-9.

4. Humbert M, Sitbon O, Chaouat A, et al. Pulmonary arterial hypertension in France: results from a national registry. Am J Respir Crit Care Med. 2006;173:1023-30.

5. Machado R, Eickelberg O, Elliott CG, et al. Genetics and genomics of pulmonary arterial hypertension. J Am Coll Cardiol. 2009;54:S32-42.

6. Sztrymf, Coulet F, Girerd B, et al. Clinical outcomes of pulmonary arterial hypertension in carriers of BMPR mutation. Am J Respir Crit Care Med. 2008;177:1377-83.

7. Cabane J, Frances C, Launay D, et al. Early detection of pulmonary arterial hypertension in systemic sclerosis: A French nationwide prospective multicenter study. Arthritis Rheum. 2005;52:3792-800.

8. Hachulla E, Gressin V, Guillevin L, et al. Prevalence and outcome in systemic sclerosis associated pulmonary arterial hypertension: application of a registry approach. Ann Rheum Dis. 2003;62:1088-93.

9. Opravil M, Sereni D. Natural history of HIV-associated pulmonary arterial hypertension:trends in the HAART era. Aids. 2008; suppl 3: S35-S40.

10. Sitbon O, Lascoux-Combe C, Delfraissy JF, et al. Prevalence of HIV-related pulmonary arterial hypertension in the current antiretroviral therapy era. Am J Respir Crit Care Med. 2008;177:108-13.

11. Le Pavec J, Souza R, Herve P, et al. Portopulmonary hypertension: survival and prognostic factors. Am J Respir Crit Care Med. 2008;178(6):637-43. 
12. Duffels MGJ, Engelfriet PM, Berger RMF, et al. Pulmonary arterial hypertension in congenital heart disease: an epidemiologic perspective from a Dutch registry. Int J Cardiol. 2007;120(2):198-204.

13. Galie N, Manes A, Palazzini M, et al. Management of pulmonary arterial hypertension associated with congenital systemic-topulmonary shunts and Eisenmenger's syndrome. Drugs. 2008;68:1049-66.

14. Lapa M, Dias B, Jardim C, et al. Cardiopulmonary manifestations of hepatosplenic schistosomiasis. Circulation. 2009;119(11):1518-23.

15. van Loon RL, Roofthooft MT, Osch-Gevers M, et al. Clinical characterization of pediatric pulmonary hypertension: complex presentation and diagnosis. J Pediatr. 2009;155:176-82.

16. Humbert M, Maître S, Capron F, et al. Pulmonary edema complicating continuous intravenous prostacyclin in pulmonary capillary hemangiomatosis. Am J Respir Crit Care Med. 1998;157:1681-5.

17. Mukerjee D, St George D, Knight C, et al. Echocardiography and pulmonary function as screening tests for pulmonary arterial hypertension in systemic sclerosis. Rheumatology. 2004;43:461-6.

18. Arcasoy SM, Christie JD, Ferrari VA, et al. Echocardiographic assessment of pulmonary hypertension in patients with advance lung disease. Am J Respir Crit Care Med. 2003;167:735-40.

19. Hachulla E, Gressin V, Guillevin L, et al. Early detection of pulmonary arterial hypertension in systemic sclerosis: A French nationwide prospective multicenter study. Arthritis Rheum. 2005;52:3792-800

20. Clayton LM, Jobsis MM, Crow JW, et al. Echocardiographic predictors of adverse outcomes in primary pulmonary hypertension. J Am Coll Cardiol. 2002;39:1214-9.

21. Forfia PR, Fisher MR, Mathai SC, et al. Tricuspid annular displacement predicts survival in pulmonary hypertension. Am J Respir Crit Care Med. 2006;174:1034-41.

22. Hummel M, Hetzer R, Ewert R. Assessment of survival in patients with primary pulmonary hypertension: importance of cardiopulmonary exercise testing. Circulation. 2002;106: 319-24.

23. Shah SJ, Thenappan T, Rich S, et al. Value of exercise treadmill testing in the risk stratification of patients with pulmonary hypertension. Circ Heart Fail. 2009;2:278-86.

24. Okajima Y, Ohno Y, Washko GR, et al. Assessment of pulmonary hypertension: What $\mathrm{CT}$ and MRI can provide. Acad Radiol. 2011;18:437-53.

25. Benza R, Biederman R, Murali S, et al. Role of cardiac magnetic resonance imaging in the management of patients with pulmonary arterial hypertension. J Am Coll Cardiol. 2008;52(21):1683-92.

26. Hoeper MM, Lee SH, Voswinckel R, et al. Complications of right heart catheterization procedures in patients with pulmonary hypertension in experienced centers. J Am Coll Cardiol. 2006;48:2546-52.

27. Sitbon O, Humbert $M$, Jais $X$, et al. Long-term response to calcium channel blockers in idiopathic pulmonary arterial hypertension. Circulation. 2005;111:3105-11.

28. Fijalkowska A, Kurzyna M, Torbicki A, et al. Serum N-terminal brain natriuretic peptide as a prognostic parameter in patients with pulmonary hypertension. Chest. 2006;129:1313-21.

29. Johnson SR, Mehta S, Granton JT. Anticoagulation in pulmonary arterial hypertension: a qualitative systematic review. Eur Respir J. 2006;28(5):999-1004.

30. Galiè N, Begh $\mathrm{M}$, Gat $\mathrm{M}$, et al. Bosentan randomized trial of endothelin antagonist therapy-5 (BREATHE-5) Investigator. Bosentan therapy in patients with Eisenmenger Syndrome: a multicenter, double-blind, randomized, placebo-controlled study. Circulation. 2006;114:48-54.

31. Barbaro G, Luccini A, Pellicelli AM, et al. Highly active antiretroviral therapy compared with HAART and bosentan in combination in patients with HIV-associated pulmonary hypertension. Heart. 2006;92(8):1164-6.

32. Cartin-Ceba R, Swanson K, Iyer V, et al. Safety and efficacy of ambrisentan for the treatment of portopulmonary hypertension. Chest. 2011;139(1):109-14.

33. Barst RJ, Rubin LJ, Long WA, et al. A comparison of continuous intravenous epoprostenol (prostacyclin) with conventional therapy for primary pulmonary hypertension. The Primary Pulmonary Hypertension Study Group. N Engl J Med. 1996;334:296-302.

34. Simonneau G, Barst RJ, Galie N, et al. Continuous subcutaneous infusion of treprostinil, a prostacyclin analogue, in patients with pulmonary arterial hypertension. A double-blind, randomized, placebo-controlled trial. Am J Respir Crit Care Med. 2002;165:800-4.

35. Olschewski H, Simonneau G, Galie N, for the AIR Study Group, et al. Inhaled iloprost in severe pulmonary hypertension. N Engl J Med. 2002;347:322-9.

36. Channick RN, Simonneau G, Sitbon O, et al. Effects of the dual endothelin-receptor antagonist bosentan in patients with pulmonary hypertension: a randomised placebo-controlled study. Lancet. 2001;358(9288):1119-23.

37. Humbert M, Barst RJ, Robbins IM, et al. BREATHE-2 combination of bosentan with epoprostenol in pulmonary arterial hypertension. Eur Respir J. 2004;24(3):353-9.

38. Sitbon O, McLaughlin VV, Badesch DB, et al. Survival in patients with class III idiopathic pulmonary arterial hypertension treated with first line oral bosentan compared with an historical cohort of patients started on intravenous epoprostenol. Thorax. 2005;60:1025-30.

39. Galiè N, Rubin L, Hoeper M, et al. Treatment of patients with mildly symptomatic pulmonary arterial hypertension with bosen$\tan$ (EARLY Study). Lancet. 2008;371:2093-100.

40. Galie N, Olschewski H, Oudiz RJ, et al. Ambrisentan for the treatment of pulmonary arterial hypertension. Results of the ambrisentan in pulmonary arterial hypertension, randomized, double-blind, placebo-controlled, multicenter, efficacy (ARIES) study 1 and 2. Circulation. 2008;117:3010-9.

41. Galie N, Ghofrani HA, Torbicki A, et al. The Sildenafil Use in Pulmonary Arterial Hypertension (SUPER) Study Group. Sildenafil citrate therapy for pulmonary arterial hypertension. New Engl J Med. 2005;353:2148-57.

42. Galie N, Brundage B, Ghofrani A, et al. Tadalafil therapy for pulmonary arterial hypertension. Circulation. 2009;119:2894-903.

43. Hoeper MM, Markevych I, Spiekerkoetter E, et al. Goal-oriented treatment and combination therapy for pulmonary arterial hypertension. Eur Respir J. 2005;26(5):858-63.

44. McLaughlin VV, McGoon MD. Pulmonary arterial hypertension. Circulation. 2006;114:1417-31.

45. Quark R, Nawrot T, Meyns B, et al. C-reactive protein: a new predictor of adverse outcome in pulmonary arterial hypertension. $\mathrm{J}$ Am Coll Cardiol. 2009;53:1211-8.

46. Henkens IR, van Wolveren SA, Gan CT, et al. Relation of resting heart rate to prognosis in patients with idiopathic pulmonary arterial hypertension. Am J Cardiol. 2009;103:1451-6.

47. Simonneau G, Rubin L, Galie N, for the Pulmonary Arterial Hypertension combination Study of Epoprostenol and Sildenafil (PACES) Study Group, et al. Addition of sildenafil to long-term intravenous epoprostenol therapy in patients with pulmonary arterial hypertension. Ann Intern Med. 2008;149:521-30.

48. McLaughlin VV, Oudiz RJ, Frost A, et al. Randomized study of adding inhaled iloprost to existing bosentan in pulmonary arterial hypertension. Am J Respir Crit Care Med. 2006;174:1257-63. combi.

49. Kurzyna M, Dabrowski M, Bielecki D, et al. Atrial eptostomy in treatment of end-stage right heart failure in patients with pulmonary hypertension. Chest. 2007;131:977-83.

50. Chen H, Shiboski SC, Golden JA, et al. Impact of the lung allocation score on lung transplantation for pulmonary arterial hypertension. Am J Respir Crit Care Med. 2009;180:385-7. 